\title{
ESCALA DE ATITUDE FRENTE À AIDS: UMA ANÁLISE PSICOMÉTRICA
}

\author{
Tokico Murakawa Moriya * \\ Elucir Gir ** \\ Miyeko Hayashida ***
}

Trata-se de um estudo metodológico que teve como objetivo construir e validar uma escala de atitudes frente a AIDS, para auxiliar no diagnóstico das atitudes favoráveis e desfavoráveis e na avaliação dos programas educativos, relacionados a AIDS. As etapas percorridas para o desenvolvimento da escala, tipo Likert, foram: elaboração de Itens relacionados à cognição, afeto e reações frente a AIDS; aplicação do instrumento numa amostra populacional, avaliação do poder discriminativo dos Itens; estudo da fidedignidade interna da escala; análise fatorial da escala para estabelecer as dimensões fundamentais do instrumento. A escala final ficou constituída de 25 Itens. O instrumento construído demonstrou um alto coeficiente de fidedignidade e validade, pela análise psicométrica.

UNITERMOS: escala de atitude, atitude frente a AIDS

\section{INTRODUÇÃO}

A desinformação, o prognóstico sombrio e as informações veiculadas pela imprensa nem sempre adequadas acerca da AIDS trouxeram a tona o medo e o pânico da população em geral. Preconceito e discriminação tornaram-se ainda mais evidentes em função da identificação de uma prevalência da AIDS em grupos sociais já estigmatizados, como de homossexuais e toxicômanos.

\footnotetext{
* Professor Associado do Departamento de Enfermagem Geral e Especializada da EERP-USP

** Assistente do Departamento de Enfermagem Geral e Especializada da EERP-USP

***Técnico Especializado de Nível Superior de Apoio ao Ensino e a Pesquisa da EERP-USP
} 
A informação e a educação do público se fez, então, premente. A única forma para conter a disseminação do HIV e os problemas decorrentes da mesma, enquanto não se dispõem de vacinas ou medicamentos eficazes para deter ou curar a AIDS, é através da informação e educação do público visando desfazer mitos e preconceitos, desenvolver e manter comportamentos que evitem o risco de contrair AIDS e comportamentos mais humanos com os portadores do HIV e aidéticos.

O comportamento, em grande parte, é explicado pelas atitudes frente ao objeto social. Assim, estudando-se as atitudes, pode-se prever o comportamento, e modificando as atitudes pode-se modificar também o comportamento. Para isto, é preciso medir as atitudes e para medir é necessário ter instrumentos confiáveis, válidos e adaptados à população alvo. No caso das atitudes, os instrumentos mais utilizados são as escalas de atitudes.

Ao realizarmos um levantamento, na literatura nacional, deparamos apenas com relatos de diversos autores sobre atitudes negativas da população em geral, no que se refere à AIDS, inclusive dos profissionais da área da saúde, entretanto, estudos científicos relacionados à atitude da população brasileira, não foram encontrados por nós.

A necessidade associada à nossa inquietação em investigar a atitude do nosso público levou-nos a realizar esta pesquisa de desenvolvimento de um instrumento para medir atitude do público frente à AIDS, com validade e fidedignidade comprovadas.

\section{Desenvolvimento da Escala}

Como afirma NEVES (1980) "independente do tipo de estudo adotado, seja ele exploratório ou explanatório, se ele for de natureza quantitativa exige a existência de indicadores do conceito, atributo, traço ou característica que está se procurando medir". Os instrumentos (indicadores) variam em suas formas e tipos dependendo do que se pretende medir .

"Os testes psicológicos são iguais aos testes de qualquer ciência, na medida em que se fazem observações sobre uma amostra pequena, mas cuidadosamente escolhida do comportamento de um indivíduo" (ANASTASI, 1977). "Assim, devem possuir certas características que, em essência, são semelhantes àquelas que se exigem dos procedimentos que se utilizam para fazer mensurações em outros campos do saber" (STEPHANECK, DA SILVA, 1985).

Um instrumento precisa demonstrar validade e fidedignidade antes de poder ser usado para medir uma variável de interesse específico. A validade e a fidedignidade são 
medidas que refletem a qualidade do instrumento; se o instrumento então não apresentar essas qualidades os resultados da pesquisa têm credibilidade limitada ou não terão utilidade prática. Fidedignidade refere-se ao grau de consistência e precisão (exatidão, minúcia) com que o instrumento mede a variável de interesse (MORAN, WILK, 1987); a validade de um teste refere-se ao que ele mede e até que ponto o faz (ANASTASI, 1977).

O objetivo do presente estudo foi construir e validar uma escala de atitude frente a AIDS. Esse instrumento deverá ser usado no estudo das atitudes das pessoas frente a AIDS, que acreditamos ser de especial importância, uma vez que o modo de reagir a ela reflete o seu comportamento, tanto em relação a si próprio, como aos outros.

\section{METODOLOGIA}

A elaboração de uma escala eficiente pressupõe um processo meticuloso que vai desde a confecção dos itens até a demonstração de sua fidedignidade e validade. Assim, faremos a descrição de cada fase do processo que realizamos para o desenvolvimento da Escala de Atitudes frente a AIDS. Para o desenvolvimento da escala contamos com assessoria de dois professores de psicologia, com domínio em psicometria, e auxílio de um técnico especializado de nível superior de apoio ao ensino e pesquisa.

\section{FASE 1: Elaboração dos itens da Escala}

Com base nas experiências profissionais vivenciadas, por nós, em numerosas palestras, conferências, cursos, reuniões e leituras de publicações científicas e populares redigimos de início 129 afirmações declarativas de atitudes positivas e negativas frente a AIDS abarcando tópicos relacionados a 1) Origem da doença (causa). 2) Conhecimento sobre a AIDS e 3) Avaliação do portador (percepções acerca do relacionamento).

Para a redação dos itens seguimos as orientações sugeridas por EDWARDS (1957), WARD (1974) e BAQUERO (1974). Formulamos sentenças afirmativas curtas, procurando utilizar vocabulários não complexos, de forma objetiva e clara. Cada afirmativa constou apenas de um pensamento completo.

Denominamos o instrumento construído sob a forma de escala de Likert de "Escala de Atitude frente a AIDS" (EA-AIDS) - Anexo. Para verificação da inteligibilidade da EAAIDS, solicitamos a uma professora de língua portuguesa que avaliasse a compreensão do conteúdo das afirmações e fizesse correrão de possíveis erros de ortografia, pontuação 
e sintaxe. As afirmações ambíguas, cujo conteúdo não apresentasse uma idéia clara e precisa, foram reformuladas.

\section{FASE 2: Validação Aparente e de Conteúdo}

Procedimentos - submetemos o conjunto das afirmações formuladas para validações aparente e de conteúdo a 10 (dez) juízes, profissionais da área de saúde envolvidos no ensino, assistência e/ou pesquisa relacionados a AIDS, todos com mais de cinco anos de experiência na área.

A escala foi apresentada pessoalmente pela pesquisadora a cada um dos juízes e explicado o objetivo e a finalidade da pesquisa. Solicitamos aos juízes, análise e sugestões quanto à clareza das afirmações, facilidades de leitura, compreensão, forma de apresentação do instrumento, abrangências e representatividade do conteúdo para medir atitudes frente a AIDS.

Solicitamos ainda que analisassem o conteúdo de cada afirmativa quanto ao seu poder discriminativo. O julgamento deveria ser expresso com a letra $\mathbf{F}$ se a afirmativa traduzisse uma atitude favorável, com a letra D se expressasse uma atitude desfavorável e com a letra I se estivesse indeciso sobre o seu posicionamento ou o item não apresentasse poder discriminativo.

Lembramos a cada um dos juízes que não estamos procurando avaliar a sua concordância ou discordância com a afirmação de cada item e que o nosso desejo era apenas saber se o conteúdo era indicador de uma atitude Favorável ou Desfavorável frente a AIDS.

Não recebemos críticas ou sugestões quanto a clareza das afirmações, facilidades de leitura, compreensão e forma de apresentação do instrumento. A escala foi considerada, por todos os juízes (100\%), abrangente e o conteúdo representativo para mensuração de atitudes dos jovens frente a AIDS.

Estabelecemos como critério de aceitação dos itens, aqueles com poder discriminativo - Favorável ou Desfavorável - igual ou superior a 80\% de concordância entre os juízes, conforme preconizado por VIANNA (1982).

Com base na apreciação dos juízes, a escala inicial de 129 afirmações foi reduzida para 111, pois 18 itens obtiveram concordância inferior ao estabelecido para aceitação.

\section{FASE 3: Avaliação do Poder Discriminativo}

Procedimento - A EA-AIDS com 111 afirmações (Anexo) foi aplicada pelo próprio pesquisador em 78 atiradores do Tiro de Guerra na faixa etária de 18 a 20 anos (Grupo A) e em 75 colegiais na faixa etária de 15 a 18 anos (Grupo B), de ambos os sexos. 
A razão da escolha desses grupos de jovens foi baseada na tentativa de obter uma amostragem heterogênea quanto a condição sócio-econômica, grau de instrução e sexo.

A EA-AIDS foi respondida em sala de aula com a aquiescência prévia do coordenador geral do Tiro de Guerra e da Diretora responsável pelo Colégio. Antes de distribuirmos os impressos explicamos o objetivo da pesquisa e solicitamos a colaboração de todos os presentes. A seguir os impressos foram distribuídos e lidas as instruções contidas na página de rosto da EA-AIDS. Frisamos que não havia resposta certa ou errada e que o importante para nós era a opinião pessoal, franca e sincera.

De posse das escalas preenchidas, realizamos a transcrição das respostas dos sujeitos a cada item, em tabelas realizando-se correção dos valores das alternativas correspondentes às atitudes negativas. A fim de verificarmos a possibilidade de reunir os dois grupos, efetuamos a somatória $(\Sigma)$, média $(\bar{x})$ e Desvio Padrão (D.P.) dos escores obtidos nas respostas dos sujeitos do Grupo A e do Grupo B, Em seguida aplicamos um Teste-T para amostras independentes (A e B) para verificar se havia diferença significativa entre os membros dos grupos. Esta análise revelou não haver diferença entre os grupos, pois a $\bar{x}$ e o $D P$ dos escores obtidos em cada grupo foram praticamente semelhantes: 0 grupo $A(n=78)$ com $\Sigma$ dos escores de 33.926 apresentou uma $\bar{x}$ de escores de 3.92 e um DP de 1.38, e o grupo $B(n=75)$ um $\sum$ de 32.346 , uma $\bar{x}$ de 3.88 e um DP de 1.38.

Também um Teste-T aplicado para cada item, separadamente, demonstrou que em apenas sete (7) deles, do total de III, apresentaram diferença significativa entre os 2 grupos de sujeitos, ou seja $p<0,05$. Esses resultados permitiram-nos agrupar os dois grupos para a realização dos cálculos para avaliar o poder discriminativo dos itens e as análises da fidedignidade e da validade da Escala.

Segundo VIANNA (1982), o limite discriminativo usualmente preconizado pelos psicometristas e sociometristas, é a de $75 \%$ de concordância.

Sendo assim, dos III itens contidos na EA-AIDS, 34 apresentaram concordância superior ao limite preconizado, ou seja, sem poder discriminativo: $3 ; 5 ; 7 ; 9 ; 10 ; 11 ; 12 ; 16$; $18 ; 19 ; 23 ; 26 ; 30 ; 37 ; 39 ; 41 ; 43 ; 44 ; 52 ; 59 ; 68 ; 69 ; 73 ; 79 ; 80 ; 81 ; 84 ; 96 ; 99 ; 101 ; 103$; $106 ; 107 ; 109$, todos eles com a opção valendo cinco (5) pontos, com exceção do item 26 , com opção valendo um (1) ponto.

\section{FASE 4: Estudos da Fidedignidade da Escala}

Procedimentos - Para se determinar o coeficiente de fidedignidade optamos pelo da coerência interna-método das metades-lançando mão do coeficiente de correlação ProdutoMomento de Pearson corrigido pela fórmula de Spearman-Brown (SB). 
A subdivisão em duas metades foi feita agrupando-se de um lado os itens pares e de outro os itens ímpares.

O coeficiente de correlação calculado entre os escores obtidos nas repostas dos itens pares e itens ímpares foi de 0,81 e o corrigido pela fórmula de Spearman-Brown foi de $0,90(p<0,001)$ demonstrando correlação bastante significativa, o que indica que a escala apresenta considerável equivalência ou adequação de amostragem dos itens. Este tipo ou coeficiente ou precisão e chamado ou coerência interna (ANASTASI, 1977).

Se um teste apresenta coerência interna considerável, segundo os dizeres de CRONBACH (1951), ele é interpretável.

\section{FASE 5: Análise Fatorial}

As diversas etapas percorridas para a análise fatorial da escala estão apresentadas sob a forma de momento.

Primeiro Momento: Quando construímos a EA-AIDS agrupamos os itens com características comuns em sub-escalas e as rotulamos de: 1) Origem da doença; 2) Conhecimento da doença; e 3) Avaliação do portador.

Deste modo, no Primeiro Momento, procuramos verificar o grau de independência desses fatores. Para isso efetuamos o cálculo das correlações Produto Momento de Pearson com 77 itens. A redução dos itens de 111 para 77 foi decorrente do fato de que 34 itens não apresentaram poder discriminativo, quando da avaliação dessa característica (Veja Fase 3).

Os resultados das correlações entre as três sub-escalas foram:

Sub-escala $1(\mathrm{n}=18) \times$ sub-escala $2(\mathrm{n}=32)=0,45$

Sub-escala $1(n=18) \times$ sub-escala $3(n=27)=0,49$

Sub-escala $2(n=32) \times$ sub-escala $3(n=27)=0,54$

Sub-escala $1(n=18) \times$ Total $(n=77)=0,74$

Sub-escala $2(n=32) \times$ Total $(n=77)=0,82$

Sub-escala $3(n=27) \times$ Total $(n=77)=0,87$

Pode-se observar facilmente que todas as intercorrelações entre as sub-escalas e também entre estas e os escores totais foram significativas ao nível de $p<0,001$. Isto se deve principalmente ao fato de a amostra utilizada (153 sujeitos) nesta pesquisa ter-se constituído de um grande número de sujeitos, o que conseqüentemente faz com que o grau de liberdade ( $\mathrm{gl}$ ) para estimação da significância da correlação de Pearson seja bastante alto e, portanto, uma correlação apenas maior que 0.30 já é significativa ao nível de 0,001. Todavia, é de nosso interesse observar que as intercorrelações entre as diversas sub-escalas foram substancialmente menores que entre as 
sub-escalas e os escores totais. Isto indica que as sub-escalas são razoavelmente diferentes entre si e que cada uma delas contribui substancialmente para a fidedignidade do instrumento proposto.

Segundo Momento: A escala constituída de 77 itens foi então submetida a uma análise fatorial com o objetivo de estabelecer as dimensões fundamentais do instrumento, proporcionando assim uma validade de constructo ao mesmo.

A análise fatorial foi realizada usando o método dos componentes principais, com rotação Varimax que indicaram 28 fatores tendo autovalores (eigenvalues-raízes características da matriz de covariancia) maiores que um $(1,0)$ - Critério de Kaiser (KAISER, 1958). Esse número grande de fatores já era esperado uma vez que a proporção entre o número de itens e o número de sujeitos é pequena (77 itens $x 153$ sujeitos).

Como mencionamos, a análise fatorial reduz um complexo conjunto de dados a apenas alguns fatores, entretanto, a nomeação desses fatores não é tarefa fácil, quanto mais nomear 28.

Terceiro Momento: A escala constituída de 77 fatores, num $3^{\circ}$ momento, foi submetida ao "Teste-T de Student" para discriminação dos itens, pois muitos deles possivelmente não estivessem se identificando com a atitude a ser medida, e conseqüentemente devessem ser retirados. Os itens selecionados, a partir do Teste-T que alcançaram maiores valores, para comporem a EA-AIDS, foram em número de 25 assim distribuídos: seis (6) na subcategoria origem da doença, onze (11) na subcategoria conhecimento da doença e oito (8) na subcategoria avaliação do portador.

Quarto Momento: A escala constituída de 25 itens puros selecionados foi submetida novamente a análise fatorial, usando a dos componentes principais, com rotação Varimax, de onde foram gerados 11 fatores com autovalores (eigenvalues-raízes características de matriz de covariança) maiores que um (1).

Dos 11 fatores gerados a partir dos valores estimados das comunidades restaram apenas quatro (4) autovalores maiores que um $(1,0)$ que explicam $58,8 \%$ da variança dos dados. Esse valor é relativamente baixo, pois conforme observa FARIA (1991), valores mais altos têm sido obtidos em trabalhos publicados em outras áreas de conhecimento, porém está dentro dos padrões usualmente encontrados na literatura.

Realizando-se a rotação dos fatores pelo critério Varimax, de forma a obter uma estrutura mais simples e de fácil interpretação verificou-se que alguns itens contribuem mais (carga acima de 0,30), ou seja, são mais importantes em cada fator.

Os Fatores 1 e 2 são carregados pelos itens relativos a origem da doença; esta característica explica $38,6 \%$ da variança dos dados. O fator 3 é mais carregado pelos itens sobre a avaliação do portador e corresponde a $11 \%$ da variança dos dados. O Fator 4 é mais 
carregado pelos itens sobre o conhecimento da doença e corresponde a 9,2\% da variança dos dados.

Os demais fatores não permitem conclusões por misturarem itens da origem da doença, conhecimento da doença e avaliação do portador.

\section{RESULTADO}

A escala iniciada com 129 itens ficou reduzida a 25, ficando assim constituída:

\section{Itens $\quad$ Afirmações}

31 - A AIDS é uma punição de Deus frente ao liberalismo do final do século XX.

32 - O uso excessivo de drogas intravenosas causou o aparecimento da AIDS.

60 - A AIDS surgiu para punir a humanidade que há muito vem se afastando de Deus.

62 - A AIDS surgiu como qualquer doença poderia ter surgido:

100 - A AIDS existe em conseqüência a um grande número de homossexuais, atualmente existente.

108 - Os homossexuais por abusarem da sexualidade, trouxeram para a humanidade o mal da AIDS.

14 - Quando a AIDS se manifesta, o resultado é sempre fatal.

15 - Pouco se sabe sobre a origem da AIDS.

17 - A proibição do homossexualismo, tal como ocorre nos países islâmicos, pode proteger o país contra a AIDS.

23 - As formas de sexo que envolvem sangramento são de alto risco para contrair AIDS.

46 - Os insetos que se alimentam de sangue humano podem transmitir a AIDS.

51 - O uso de vaselina, durante a relação sexual, previne a AIDS.

61 - As pessoas que freqüentam saunas correm risco de contrair a AIDS.

66 - O banheiro público é um local que pode transmitir a AIDS.

85 - O motel nada tem a ver com local que transmite AIDS.

97 - A AIDS pode ser curada se detectada precocemente.

98 - A AIDS é causada por um vírus denominado HIV.

20 - Realizar teste para se detectar possível portador do vírus da AIDS, como exame préadmissional em qualquer emprego, é um ato discriminatório.

22 - O portador da AIDS tem direito a continuidade de sua vida civil, profissional, sexual e afetiva. 
27 - É um ato reprovável, impedir a freqüência de alunos em escolas, cujos pais estejam contaminados com o vírus da AIDS.

36 - É preciso afastar hemofílicos, homossexuais, usuários de drogas injetáveis, de empregos e escolas afim de proteger os demais colegas.

48 - Crianças contaminadas com AIDS requerem salas especiais para se evitar contatos com outros alunos.

55 - Hospitais só para AIDS são desnecessários para proteger a população do perigo de contaminação.

72 - Os portadores da AIDS devem ser tratados sem discriminação.

93 - Deve ser vedada a participação de portadores da AIDS de atividades coletivas, escolares e militares.

Os itens de números 31, 32, 60, 62, 100 e 108 correspondem a sub-escala "origem da doença"; os itens 14, 15, 17, 26, 46, 51, 61, 66, 85, 97 e 98 correspondem a sub-escala "conhecimento sobre a doença" e os itens 20, 22, 27, 36, 48, 55, 72 e 93 são relacionados a "avaliação do portador".

\section{CONSIDERAÇÕES FINAIS}

As razões que nos levaram a esta escolha de medida de atitude através de relatos pessoais, adotando a escala do tipo Likert de avaliações cumulativas foram: 1) a nossa postura teórica e profissional pressupõe estar o comportamento verbal de uma pessoa manifesto nas respostas de uma escala, relacionado às suas atitudes reais e ao comportamento não verbal apresentado pela mesma; 2) devido a algumas vantagens atribuídas à escala do tipo Likert como as destacadas por RAGAZZI (1976), tais como, maior facilidade quanto a sua elaboração e construção; é um método que produz escalas mais homogêneas e aumenta a probabilidade de mensuração de atitudes unitárias; baseiase em dados empíricos relacionados a respostas dos sujeitos, antes que as opiniões dos juízes; permite maior amplitude de respostas a cada item.

BAQUEIRO (1974), NUNNALLY (1970) e CRONBACH (1970) sugerem a construção de maior número possível de afirmações de início, para que a versão final da escala contenha número suficiente de itens. A escala iniciada com 129 afirmações ficou restrita na sua forma definitiva a 25 . Houve então uma redução do número de itens em torno de cinco vezes do inicial. NUNNALL Y (1970) refere que o número de itens iniciais a serem formulados deve ser em torno de duas $(2)$ a duas vezes e meia $(2,5)$ mais do que o número pretendido para o instrumento definitivo.

Julgamos bastante adequado o número de itens de nossa escala definitiva, pois com 25 , acreditamos abarcar itens representativos de que apresenta facilidade de aplicação e de 
cálculos estatísticos em micro computador. Uma escala extensa pode ser cansativa desmotivando os respondentes e exporem suas respostas reais.

Os testes realizados para verificar a homogeneidade entre os dois grupos demonstraram não haver diferença significante entre eles, o que nos permitiram agrupá-los num só para a realização da testagem do instrumento.

Os resultados alcançados através da análise psicométrica que mostraram um alto coeficiente de fidedignidade (precisão) e de comprovação da validade, nos autorizam a dizer que o instrumento elaborado pode ser considerado bom e, portanto, permite a sua utilização para avaliar atitudes frente a AIDS.

É um trabalho pioneiro no Brasil, na área de AIDS. Estudos dessa natureza visando ao desenvolvimento de estratégias de coletas de dados com evidências garantidas de validade e fidedignidade são escassos na literatura brasileira. CASSIANI (1987), realizando estudos para verificar quais estratégias de coletas de dados utilizadas nas pesquisas em enfermagem, e o que os pesquisadores fazem para garantir a sua validade e a fidedignidade, concluiu que a maioria das pesquisas utiliza a entrevista, questionário, formulário, medidas fisiológicas e observações como estratégias e estas não citam, em sua maioria, a utilização do procedimento para evidenciarem a validade e a confiabilidade das mesmas.

O processo de construir e validar um instrumento de pesquisa e extremamente laborioso, razão pela qual, possivelmente, muitos trabalhos de pesquisa facultem essa etapa. Entretanto, se pretendemos que os resultados da pesquisa sejam considerados de credibilidade científica ou que tenham utilidade prática, é importante a demonstração da validade e fidedignidade da estratégia de coleta de dados utilizada.

Os resultados alcançados, em nosso estudo, comprovaram ser EA-AIDS, um instrumento fidedigno é válido, após criteriosa análise psicométrica.

Estudos dessa natureza, em enfermagem, ainda são incipientes no Brasil. A divulgação do presente estudo com a descrição de como foi realizada, passo a passo, desde a elaboração dos itens até as medidas de validade e fidedignidade possivelmente será de grande valia a enfermagem que dispõe de poucas informações quanto ao método para executar este tipo de pesquisa.

Embora a EA-AIDS tenha demonstrado alto coeficiente de fidedignidade e validade, pode conter falhas, que possivelmente sério detectados quando de sua aplicação prática. Outros tipos de análise psicométrica também são desejáveis, como por exemplo, a de validade preditiva e de validade concomitante. Pretendemos, assim, numa etapa posterior, aplicá-la e realizar os possíveis refinamentos que forem necessários. 


\section{A SCALE OF A TTITUDES CONCERNING AIDS: A PSYCHOMETRICAL ANALYSIS}

The objective of the present methodological study was to construct and validate a scale of altitudes of people concerning AIDS, to aid in the diagnosis of favorable and unfavorable attitudes and evaluation of educational programs related to AIDS. The steps followed to develop the Likert-type scale were: elaboration of items related to knowledge, feelings and reactions about AIDS; apparent validation and verification of content; application of the instrument it' a sample of people; evaluation of the ability to discriminate the items; study of the internal reliability of the scale; factor analysis of the scale to establish the fundamental dimensions of the instrument. The final scale contained 25 items. This instrument showed a high coefficient of reliability and validity.

UNITERMS: scale of attitude, attitude to AIDS

\section{ESCALA DE ACTITUDES FRENTE AL SIDA: UNA ANÁLISIS PSICOMÉTRICA}

Este estudio metodológico tuvo como objetivo construir y validar una escala de actitudes frente al SIDA, para auxiliar en el diagnóstico de las actitudes favorables $y$ desfavorables y en la evaluación de los programas educativos, relacionados con el SIDA. Las etapas investigadas para el desarrollo de la escala, tipo Likert, fueron: elaboración de ítems relacionados a la cognición, afecto y reacciones frente al SIDA; validación aparente y de contenido; aplicación del instrumento en una muestra poblacional; evaluación del poder discriminador de los ítems; estudio de la autenticidad interna de la escala; $y$, análisis factorial para establecer las dimensiones fundamentales del instrumento. El instrumento construido ha demostrado un alto coeficiente de autenticidad y validez.

UNITERMOS: escala de actitud, actitud frente al SIDA 


\section{REFERÊNCIAS BIBLIOGRÁFICAS}

01. ANASTASI, A. Testes psicológicos. Trad. Dante Moreira Leite. 2. ed. São Paulo: EPU, 1977.

02. BAQUERO, G. Testes psicométricos e projetivos: medidas psico-educacionais. São Paulo: Loyola, 1974.

03. CASSIANI, S .H.B. A coleta de dados nas pesquisas em Enfermagem. Estratégias, validade e confiabilidade. Ribeirão Preto. 156 p. Dissertação (mestrado) - Escola de Enfermagem de Ribeirão Preto, Universidade de São Paulo, 1987.

04. CRONBACH, L.J. Coefficient alpha and the internal structure of the tests. Psychometrika, v. 19, n. 1, p. 297-334, 1951.

05. CRONBACH, L.J. Essentials of psychological testing. 3. ed. New York: Harper and Row, 1970.

06. EDWARDS, A.L. Techniques of attitude scale construction. New York: Appleton Century Crofts, 1957.

07. FARIA, C.A. Avaliação do nível de serviço de transporte coletivo urbano sob o ponto de vista do usuário: o enfoque multivariado. São Paulo, 158 p. Tese (Doutorado) - Escola Politécnica. Universidade de São Paulo, 1991.

08. KAISER, H.F. The varimax criterion for analytic rotation in factor analysis. Psychometrika, v. 23, p. 187-200, 1958.

09. MORAN, V., WILK, J.R. Continuing education approval program: interrater reliability. J. Continuing Education Nurs., v. 18, n. 2. p. 44-46, 1987.

10. NEVES, E.P. Validade e confiabilidade de instrumentos de coleta de dados. Florianópolis: UFSC, 1980. 12 p. (mimeografado).

11. NUNNALY, J.C. Introducción a la medición psicológica. México: McGraw-Hill, 1970.

12. RAGAZZI, N. Uma escala de atitudes em relação à matemática. São Paulo, 150 p.

Dissertação (Mestrado) - Instituto de Psicologia, Universidade de São Paulo, 1976.

13. STEPHANECK, P., DA SILVA, J.A. Medidas, escalas e decisão em psicologia.

Ribeirão Preto: Faculdade de Filosofia, Ciências e Letras de Ribeirão Preto. Universidade de São Paulo, 1985. 127 p. (mimeografado).

14. VIANNA, H.M. Testes em educação. São Paulo: IBRASA, 1982.

15. WARD , C .D. Psicologia social experimental. Trad. Ana Edith Bellico da Costa e Nilza Rocha Féres. São Paulo: EPU/EDUSP, 1974. 


\section{ANEXO \\ ESCALA DE ATITUDE FRENTE A AIDS \\ (EA-AIDS)}

Concordo totalmente

Concordo em parte

Estou em dúvida.

Discordo em parte

Discordo totalmente

01. A AIDS surgiu para fazer uma seleção natural da humanidade, eliminando homossexuais, hemofílicos e usuários de drogas

02. A AIDS foi criada em laboratório por cientistas para ser usada como arma biológica.

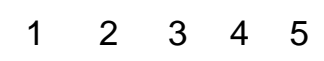

03. Somente os depravados sexualmente contraem AIDS.

04. A AIDS veio confirmar a peste prometida a humanidade, segundo profecias passadas

05. A AIDS é uma invenção dos moralistas, para frear a liberdade sexual.

06. Pessoas contaminadas com AIDS devem ser afastadas do convívio social

07. A AIDS atinge apenas os homossexuais......

$\begin{array}{lllll}1 & 2 & 3 & 4 & 5\end{array}$

08. A pessoa com AIDS merece apenas piedade

$\begin{array}{lllll}1 & 2 & 3 & 4 & 5\end{array}$

09. A pessoa com AIDS merece respeito humano como qualquer outro cidadão

$\begin{array}{lllll}1 & 2 & 3 & 4 & 5\end{array}$

10. A AIDS só se transmite entre pessoas do sexo masculino

$\begin{array}{lllll}1 & 2 & 3 & 4 & 5\end{array}$

11. O vírus da AIDS pode permanecer no corpo, durante anos, sem manifestar sintomas ou sinais visíveis

12. Até o momento a AIDS é incurável.....

$\begin{array}{lllll}1 & 2 & 3 & 4 & 5\end{array}$

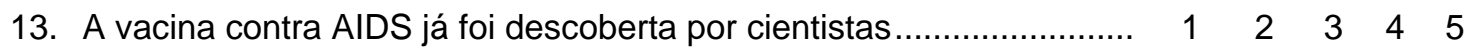

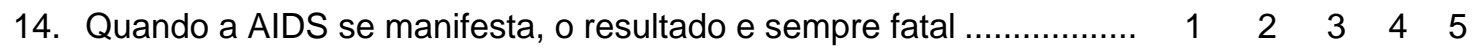

15. Pouco se sabe sobre a origem da AIDS......................................... $11 \quad 2 \quad 3 \quad 3 \quad 4 \quad 5$

16. A pessoa que tem numerosos parceiros sexuais está mais propensa a contrair AIDS

17. A proibição do homossexualismo, tal como ocorre nos países islâmicos pode proteger o país contra AIDS

8. A prevenção e o controle da AIDS é de responsabilidade individual e coletiva

19. A prática de cultos como candomblé, macumba e outras crenças pode levar a cura da AIDS.

20. Realizar teste para se detectar possível portador do vírus da AIDS, como exame pré-admissional em qualquer emprego, é um ato discriminatório

21. Já existem no mercado medicamentos eficazes para a cura da AIDS $1 \begin{array}{llllll}1 & 2 & 3 & 4 & 5\end{array}$ 
22. O portador da AIDS tem direito a continuidade de sua vida civil, profissional, sexual e afetiva.

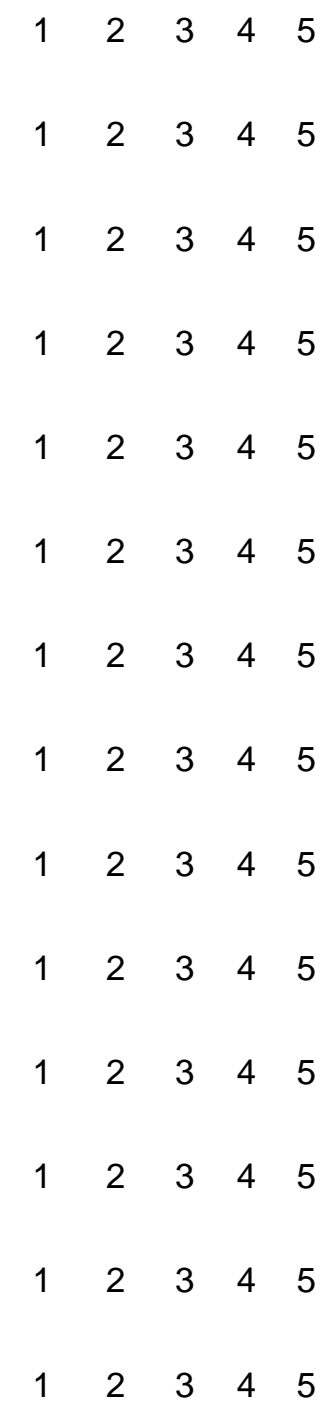

$\begin{array}{lllll}1 & 2 & 3 & 4 & 5\end{array}$

$\begin{array}{lllll}1 & 2 & 3 & 4 & 5\end{array}$

$\begin{array}{lllll}1 & 2 & 3 & 4 & 5\end{array}$

23. As formas de sexo que envolvem sangramento são de alto risco para contrair AIDS

24. É necessário demitir funcionários contaminados com AIDS de seu emprego para proteger os demais.

25. Alunos contaminados com o vírus da AIDS ou com suspeita devem ser afastados das escolas

26. Deve se construir hospitais específicos para AIDS a fim de proteger outros pacientes.

27. É um ato reprovável, impedir a freqüência de alunos em escolas, cujos os pais estejam contaminados com o vírus da AIDS

28. Vilas ou comunidades especificas para abrigar pessoas com AIDS é a solução para prevenir a sociedade contra tal doença.

29. É importante a divulgação de nomes de pessoas contaminadas com a AIDS como medida de prevenção para outras pessoas

0. A AIDS é uma nova doença que até hoje é considerada incurável e é fatal

31. A AIDS é uma punição de DEUS frente ao liberalismo do final do século $X X$

32. O uso excessivo de drogas intravenosas causou o aparecimento da AIDS.

33. Qualquer pessoa esta sujeita a adquirir AIDS se for está à vontade divina.

34. Queimar pertences de pessoas que morrem de AIDS é uma medida de prevenção recomendada

35. Pode-se adquirir AIDS morando em casa que foi habitada por uma pessoa com essa doença

36. É preciso afastar hemofílicos, homossexuais, usuários de drogas injetáveis, de empregos e escolas afim de proteger os demais colegas.

37. O uso de camisinhas, durante o ato sexual, diminui o risco de contrair a AIDS

38. A AIDS é mais freqüente entre pessoas de baixa condição sócioeconômica

39. É necessário ter compreensão e solidariedade para com o portador do vírus da AIDS.

40. Contatos casuais simples como abraçar, cumprimentar e beijar socialmente não transmitem AIDS

41. Só quem é azarado contrai AIDS

42. Os hospitais e unidades de saúde devem dar assistência a pacientes com AIDS sem qualquer restrição

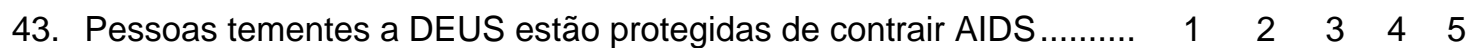

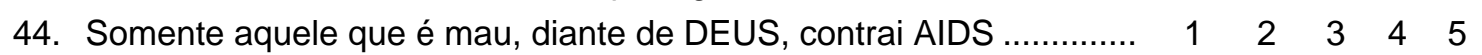

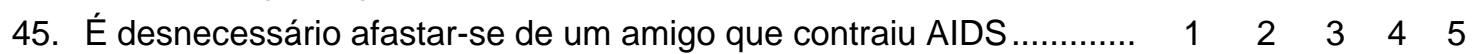


46. Os insetos que se alimentam de sangue humano podem transmitir AIDS.

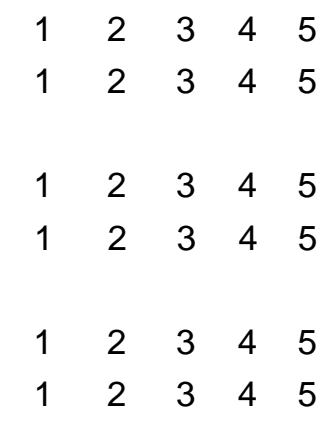

$\begin{array}{lllll}1 & 2 & 3 & 4 & 5\end{array}$

$\begin{array}{lllll}1 & 2 & 3 & 4 & 5\end{array}$

$\begin{array}{lllll}1 & 2 & 3 & 4 & 5\end{array}$

47. A carne, quando ingerida crua, pode transmitir a AIDS

48. Crianças contaminadas com AIDS requerem salas especiais para se evitar contatos com outros alunos

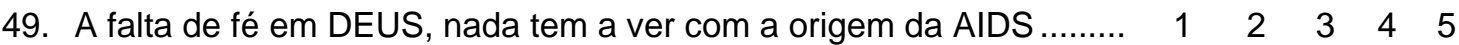

50. Nem todas as pessoas necessitam fazer teste para saber se estão contaminadas com AIDS

51. O uso de vaselina; durante a relação sexual, previne a AIDS

52. Aquele que ingere grande quantidade de álcool está livre de contrair a AIDS

53. Eliminando-se os homossexuais, toxicômanos e hemofílicos da sociedade livra-se também da AIDS

$\begin{array}{lllll}1 & 2 & 3 & 4 & 5\end{array}$

4. As prostitutas são as principais responsáveis pela disseminação da AIDS.

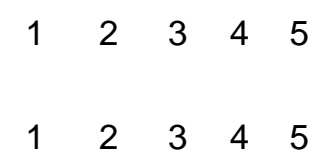

55. Hospitais só para AIDS são desnecessários para proteger a população do perigo de contaminação.

56. É impossível distinguir a pessoa portadora do vírus da AIDS Pelo aspecto físico e comportamental...

57. Crianças portadoras do vírus da AIDS podem freqüentar escolas públicas junto com as demais crianças

$\begin{array}{lllll}1 & 2 & 3 & 4 & 5\end{array}$

58. Algumas pessoas já nascem com tendência a adquirir AIDS...

59. A AIDS é um pretexto das indústrias farmacêuticas para lançamento de novos medicamentos.

60. A AIDS surgiu para punir a humanidade que há muito vem se afastando de DEUS.

61. As pessoas que freqüentam saunas correm risco de contrair AIDS...

62. A AIDS surgiu como qualquer outra doença poderia ter surgido .........

63. Deixar de freqüentar piscinas públicas nada tem a ver como medida de prevenção da AIDS

$\begin{array}{lllll}1 & 2 & 3 & 4 & 5 \\ 1 & 2 & 3 & 4 & 5 \\ 1 & 2 & 3 & 4 & 5\end{array}$

64. Usar preservativos nas relações sexuais é uma forma de prevenção da AIDS.

65. A família que tem uma pessoa contaminada com AIDS é discriminada pela sociedade

66. O banheiro público é um local que pode transmitir a AIDS..................

67. A piscina pública pode transmitir a AIDS........................................
68. Usar seringas e agulhas descartáveis e individuais é uma das medidas de prevenção a AIDS

69. Escolher melhor seus parceiros sexuais é uma das medidas de prevenção a AIDS

70. A AIDS surgiu para mostrar que, pessoas que contaminam a moral social, devem ser eliminadas.

71. Uma boa higiene, após o ato sexual, com água e sabão previne a AIDS.

72. Os portadores da AIDS devem ser tratados sem discriminação... 
73. A AIDS provém do abuso das pessoas, no consumo de medicamentos, sem prescrição médica

$\begin{array}{lllll}1 & 2 & 3 & 4 & 5 \\ 1 & 2 & 3 & 4 & 5 \\ 1 & 2 & 3 & 4 & 5\end{array}$

74. A AIDS é uma doença misteriosa que ninguém vai descobrir sua origem .

76. A AIDS pode ser transmitida através de utensílios como copos, xícaras, talheres e pratos.

$\begin{array}{lllll}1 & 2 & 3 & 4 & 5\end{array}$

77. Evitar visitas a hospitais e enfermarias diminui a possibilidade de adquirir AIDS.

78. Pessoas que agridem a sociedade com comportamentos antisociais devem ser eliminados da mesma, através da AIDS

79. A AIDS é um pretexto, usado pelos moralistas, para frear a liberação sexual e o uso de tóxicos.

80. Aquele que crê em DEUS e pratica uma religião está livre de adquirir AIDS.

81. O vírus da AIDS enfraquece o sistema de defesa do corpo tornando-o vulnerável a qualquer infecção

82. A falta de condições higiênicas promove o desenvolvimento da AIDS

83. É impossível distinguir a pessoa portadora do vírus da AIDS Pelo aspecto físico e comportamental.

84. Tratamento espiritual é a única forma de curar a AIDS

85. 0 motel nada tem a ver com local que transmite AIDS

86. Evitar saunas é uma medida de prevenção da AIDS

87. A prevenção da AIDS depende da mudança de comportamento da sociedade frente a sexualidade humana.

88. O portador do vírus da AIDS deve ser isolado da sociedade

88. O portador do vírus da AIDS deve ser isolado da sociedade...............

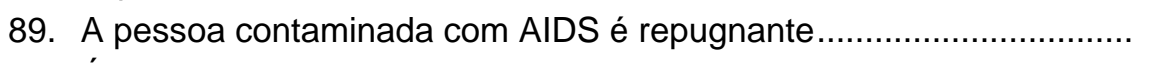

90. É necessário restringir a liberdade e os direitos de uma pessoa portadora da AIDS para se evitar a contaminação de outras pessoas....

1. O portador da AIDS tem direito a participação em todos os

92. Toda ação que tende a recusar ou privar os portadores da AIDS de emprego, alojamento, assistência deve ser desprezada

93. Deve ser vedada a participação de; portadores da AIDS de atividades coletivas, escolares e militares.

94. A privacidade dos portadores de AIDS deve ser respeitada e

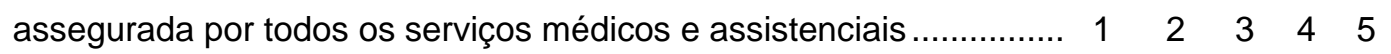

95. Urinar após o ato sexual é uma forma de prevenção da AIDS ........... $1120 \begin{array}{lllll}2 & 2 & 4 & 5\end{array}$

96. A origem da AIDS é devido ao enfraquecimento do corpo

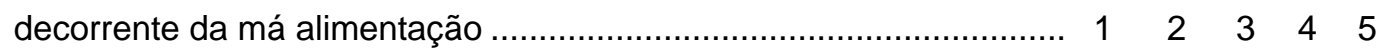

97. A AIDS pode ser curada se detectada precocemente ....................... $1120 \begin{array}{lllll}2 & 3 & 4 & 5\end{array}$

98. A AIDS é causada por um vírus denominado HIV.............................. $1122 \begin{array}{lllll}2 & 3 & 4 & 5\end{array}$

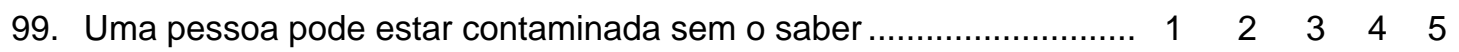

100. A AIDS existe em conseqüência a um grande número de homossexuais, atualmente existente 
101. A AIDS é decorrente do uso de agrotóxicos de forma excessiva nos produtos alimentícios

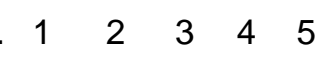

102. Hábitos higiênicos pessoais precários são condições que favorecem o surgimento da AIDS......

103. A AIDS é resultante da reprodução rápida de mosquitos e outros insetos que infestam cada vez mais o nosso planeta

104. A AIDS é o mal do século que, como está escrito na Bíblia, vem purificar a humanidade....

105. Todo e qualquer tipo de droga faz originar a AIDS, já que enfraquece o organismo

106. A AIDS surgiu dos abusos das indústrias farmacêuticas que alteram os medicamentos

107. A AIDS provém da poluição atualmente existente em grande quantidade

108. Os homossexuais por abusarem da sexualidade, trouxeram para a humanidade o mal de AIDS

109. A deficiência alimentar, própria dos dias atuais, trouxe como conseqüência a AIDS

110. A boemia propiciou o aparecimento da AIDS, que se origina da vida desregrada

111. As más condições de higiene propiciam a proliferação do vírus da AIDS 